\title{
De loopbaan van de klerk Melis Stoke 86
}

\section{J.W.J. BURGERS}

Een van de belangrijkste bronnen voor onze kennis van de geschiedenis van het graafschap Holland en Zeeland aan het eind van de dertiende en het begin van de veertiende eeuw wordt gevormd door de Rijmkroniek van Holland. Dit werk is, naar wordt aangenomen, geschreven door de grafelijke klerk Melis Stoke. Zijn kroniek is vooral van belang omdat daarin door een goed-geïnformeerde auteur uitvoerig, en in een levendige stijl, verslag wordt gedaan van de dramatische politieke gebeurtenissen in de jaren 1295-1305. Dank zij dit relaas zijn we bijvoorbeeld op de hoogte van de toedracht van de moorden op graaf Floris V en Wolfert van Borsele, en kennen we het verloop van de Vlaamse oorlog, die Holland op de rand van de afgrond bracht. Daarbij komt dat de Rijmkroniek een waar monument is van de Nederlandse taal. De kroniek is een van de oudste volledig overgeleverde literaire teksten in de volkstaal, voor de Noordelijke Nederlanden zelfs de alleroudste, en het eerste voorbeeld van het genre van de rijmkroniek. Ook voor taal- en literatuurhistorici is dit werk dus van groot belang. Al met al zijn er genoeg redenen om te proberen de vele problemen op te lossen, die nog met het ontstaan en het auteurschap van de kroniek samenhangen ${ }^{87}$.

De recentste editie van de Rijmkroniek dateert uit 1885. De uitgever ervan, W. G. Brill, gaf toen als bijlage een facsimile van een oorkonde van graaf Willem III van Holland, uitgevaardigd op 29 november 1305, en bestemd voor de stad Zierikzee ${ }^{88}$. Dit stuk is links onderaan, door dezelfde hand als die de tekst schreef, ondertekend met de naam $a$. stoke. Volgens Brill hebben we hier voor ons een oorkonde die eigenhandig is geschreven door Amelis (oftewel Melis) Stoke, de auteur van de Rijmkroniek. Sindsdien heeft niemand deze conclusie van Brill in twijfel getrokken, maar evenmin is er ooit iets met die vondst gedaan.

Enige tijd geleden stuitte ik op Brills facsimile, in het kader van een uitgebreid onderzoek naar het schrift in de documentaire bronnen in Holland en Zeeland in de dertiende eeuw. Ik herkende het handschrift van de oorkonde meteen: dit was een notarius uit de Hollandse grafelijke kanselarij die al door J. G. Kruisheer in diens proefschrift was geïdentificeerd, waar hij kanselarijhand U heet ${ }^{89}$. Ook M. Gysseling had in zijn monumentale editie van het Corpus van Middelnederlandse teksten deze

\footnotetext{
86 De in deze lezing in voorlopige vorm bekend gemaakte ontdekking over Melis Stoke is, samen met de daaruit voortvloeiende nieuwe bestudering van de Rijmkroniek, onderwerp van een thans lopend onderzoek door de auteur.

87 Voor een overzicht van literatuur, edities en de discussie met betrekking tot de Rijmkroniek zie M. Carasso-Kok, Repertorium van verhalende historische bronnen uit de middeleeuwen ('s-Gravenhage, 1981) 388-390, no. 358, alsmede de hierna genoemde literatuur ter zake.

88 Rijmkroniek van Melis Stoke, W. G. Brill, ed. (2 din.; Utrecht, 1885; ongew. herdr. in één band; Utrecht, 1983). Het facsimile staat in deel 2 vooraan op de ongenummerde pagina's, in de herdruk achter in het boek. De betreffende oorkonde berust in het gemeentearchief van Zierikzee, nr. 21.
}

89 Kruisheer, Oorkonden en kanselarij, I, 42-43. 


\section{Voor een goede weergave van de afbeeldingen, zie de gedrukte versie}

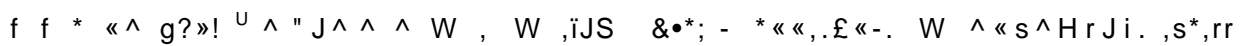

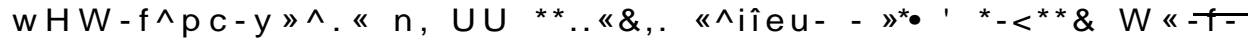

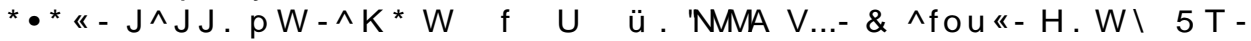

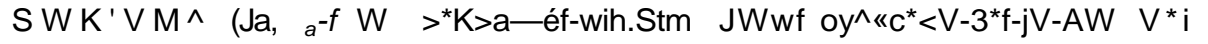

\section{'i mj.}

Afb. 1 Schepenen van Dordrecht oorkonden dat Hendrik heer Gerardszoon 75 pond nieuwe Engelse penningen schuldig is aan Jan Bones of aan toonder, 1296 juli 30. GA Dordrecht, Stadsarchief 1200-1572, no. 617, regest no. 91. Dit is de vroegst bekende door Melis Stoke geschreven oorkonde.

Foto: GA Dordrecht

Vèr\&ffc, $t^{\wedge}$ é A t t O r » $-^{\wedge}$ Sortir- $\left(4^{\prime}\right.$ àl^^^irijfldv- « $4^{\wedge} a^{\wedge} . S^{\wedge} H c-A ̈ v 4 i \ll ! S »$

Afb. 2 Graaf Jan II bevestigt de burgers van Haarlem in hun stedelijke voorrechten, 1299 dec.

23. GA Haarlem, inv.-Enschedé, no. 13. De oorkonde is geschreven door Melis Stoke.

Foto: GA Haarlem 
hand geïdentificeerd en in de kanselarij van de graven van Holland gelokaliseerd ${ }^{90}$. Beide auteurs brachten deze scribent evenwel niet in verband met Melis Stoke, blijkbaar omdat de door Brill gepubliceerde oorkonde zich juist een paar jaar voorbij de door Kruisheer en Gysseling niet overgestoken eeuwgrens bevindt. Aan eventuele paleografische problemen kan het niet liggen dat Stokes schrift niet al eerder is geïdentificeerd: hij heefteen duidelijk persoonlijke schrijfstijl, die weinig veranderlijk is, en gemakkelijk te onderscheiden van die van contemporaine handen. Wanneer men eenmaal vertrouwd is met dit schrift, een zwierige en tegelijk krachtige oorkondencursief, herkent men het in één oogopslag (zie afb. 1 en 2$)^{91}$.

Met deze ontdekking was het moment gekomen dat de vondst van Brill zijn vruchten kon gaan afwerpen. We hebben nu de beschikking over niet één, maar een hele reeks van oorkonden die door Stoke eigenhandig zijn gemundeerd (in het net geschreven). Wanneer we de in de oorkondenleer ontwikkelde onderzoeksmethoden op dit corpus gaan toepassen, zullen we zeker het een en ander te weten komen over de tot nu toe schimmige figuur van Melis Stoke, en over zijn ambtelijke carrière. Dat kan weer tot gevolg hebben dat meer bekend wordt over het ontstaan van de Rijmkroniek.

De eerste vraag die we ons in dit verband moeten stellen luidt: heeft inderdaad Melis Stoke zélf die oorkonde uit 1305 geschreven, en daarmee alle andere van de kanselarijhand $\mathrm{U}$ ? Het is immers op voorhand niet uit te sluiten dat een andere klerk dat stuk mundeerde, en daarna eronder de naam noteerde van zijn superieur, onder wiens verantwoordelijkheid de akte was vervaardigd ${ }^{92}$. Bovendien was het in deze tijd in de grafelijke kanselarij helemaal niet de gewoonte dat uitgaande stukken werden gesigneerd. Hoe is in dit geval deze klerk dan op het idee gekomen om een oorkonde wèl te ondertekenen?

Wat de laatste vraag betreft, er waren rond 1300 al wel voorbeelden van kanselarijen waarin de uitgaande stukken inderdaad werden gesigneerd, en wel steeds eigenhandig door de scriptor van de oorkonde. Een klerk in de Hollandse grafelijke kanselarij, die toegang had tot het archief, zal dus wel met het verschijnsel van de gesigneerde oorkonden bekend zijn geweest. De pauselijke bullen kenden al lang dienstaantekeningen, notarissen voorzagen hun akten van een ondertekening en signet, en bovendien signeerden de ambtenaren van de Franse koning de door hen vervaardigde stukken, links onderaan op de pliek ${ }^{93}$. Het zal wel dit laatste voorbeeld zijn dat in 1305

90 Gysseling, CMT, 1-4, kopnoot bij no. 1826.

91 Voor een uitgebreide paleografische beschrijving van het schrift van Melis Stoke zie Burgers, 'Paleografie documentaire bronnen', onder kanselarijhand T. Stoke kende, net als de meeste andere scribenten uit zijn tijd, geen vaste spelling. Zo is in de hier afgebeelde oorkonden te zien hoe hij in 1296 'beseghelt' en 'seghelen' schrijft, met een $s$, terwijl hij in 1299 deze woorden met een $z$ vormt: 'bezeghelt' en 'zeghele'.

92 Zoals eerder in de Datum per manus-formule de naam van het hoofd van de kanselarij werd genoemd. Het optreden van die dataris, die oorkonden controleerde maar ze nooit opstelde of mundeerde, zien we in de Hollandse grafelijke oorkonden echter slechts in het begin van de dertiende eeuw, en in de koningsoorkonden van graaf Willem II; zie hierover Kruisheer, Oorkonden en kanselarij, 1,99-100,186190.

93 Over de gebruiken in de verschillende kanselarijen zie P. Bonenfant, Cours de diplomatique, II, Diplomatique spéciale (Luik, 1948²) i.h.b. 65, 73, 96. 
door de Hollandse grafelijke notarius is nagevolgd; uit Frankrijk afkomstige gewoonten en vormen werden toen immers gretig overgenomen. Overigens wordt in de Hollands-Henegouwse kanselarij pas vanaf de jaren dertig van de veertiende eeuw signering van uitgaande oorkonden een vast gebruik, maar al eerder komen door grafelijke klerken ondertekende stukken voor, zij het sporadisch $^{94}$.

Twee van die vroege gevallen zijn voor ons bijzonder interessant. Onlangs heeft J. G. Smit een oorkonde gevonden, die alleen in afschrift is overgeleverd, en die op 2 juni 1304 is uitgevaardigd door Willem, oudste zoon van graaf Jan II; dit stuk is eveneens ondertekend met de naam 'A. Stoke ${ }^{95}$. Op 22 november 1305 vaardigde dezelfde, intussen graaf Willem III geworden, een oorkonde uit, die weer de signering $a$. stoke draagt. Deze laatste oorkonde is wèl in origineel overgeleverd, en blijkt inderdaad te zijn geschreven èn ondertekend door onze notarius, de kanselarijhand $\mathrm{U}^{96}$.

De genoemde overwegingen, dus enerzijds de rond 1300 elders al gangbare praktijk van eigenhandige signering door de klerk die een oorkonde schreef, welke praktijk later ook in de Hollandse grafelijke kanselarij ingang vond, en anderzijds het feit dat twee stukken door eenzelfde scribent $U$ zijn gemundeerd en ondertekend, rechtvaardigen de conclusie dat het wel zeker is dat hand $U$ inderdaad toebehoorde aan Melis Stoke. Vooruitlopend op het volgende kan hieraan nog worden toegevoegd dat Stoke de tekst van de door hem geschreven oorkonden zelf redigeerde; ook de eerder genoemde oorkonde uit 1304, welke zijn ondertekening draagt maar slechts in afschrift bewaard is gebleven, blijkt door hem te zijn opgesteld. Het lijkt er dus op dat hij persoonlijk de hand had in alle fasen van de vervaardiging van de stukken. Een en ander versterkt de conclusie dat de ondertekeningen, en daarmee alle door hand $U$ geschreven oorkonden, autografen zijn van Melis Stoke.

Als volgende stap werd het totale corpus van de door Stoke geschreven oorkonden vastgesteld. Daartoe zijn de toeschrijvingen door Kruisheer en Gysseling opnieuw bekeken, en in de meeste gevallen valide bevonden. Een klein aantal stukken van vóór de eeuwwisseling kon nog aan dit geheel worden toegevoegd. Voorde periode na 1300 werden in de Hollandse en Zeeuwse archieven alle originele oorkonden uit de jaren 1301 -1310 bekeken, en in een aantal archieven buiten deze territoria de in deze jaren door de Hollandse graven uitgevaardigde oorkonden. Deze speurtocht leverde nog een flink aantal stukken op. Uiteindelijk konden 39 originele oorkonden worden toegeschreven aan de hand van Melis Stoke, en daarnaast twee door hem opgetekende oorkonden in het oudste grafelijke cartularium. De eerste door hem geschreven oorkonde dateert van 30 juli $1296^{97}$, de laatste is het stuk waar alles mee begon, de

94 Zie Th. van Riemsdijk, De tresorie en kanselarij van de graven van Holland en Zeeland uit het Henegouwsche en Beyersche huis ('s-Gravenhage, 1908) 62-69 en 79-101.

95 J. G. Smit, 'De klerk Melis Stoke en Zierikzee in 1304. Een nieuwe archiefvondst', Kroniek van het land van de zeemeermin (Schouwen-Duiveland), XV (1990) $31-36$.

96 Rijksarchief in Antwerpen, fonds Biezelinge (ongenummerd); H. Obreen, ed., 'Onuitgegeven oorkonden uit de 13de eeuw, betreffende het klooster Jeruzalem onder Biezelinge op Zuid-Beveland', Bijdragen en mededelingen van het Historisch Genootschap (gevestigd te Utrecht), XXXIII (1912) 107-108.

97 Gemeentearchief Dordrecht, I, no. 617, regest nr. 91; uitg. in Gysseling, CMT, 1-4, 2301-2302, nr. 1517 , met een foutieve identificatie van de hand. Zie afb. 1. 
oorkonde van 29 november 1305. De meeste door Stoke geschreven stukken hebben het Nederlands als voertaal, vijf zijn in het Latijn gesteld, en twee in het Frans.

Aan de hand van deze oorkonden kunnen we nu meer te weten komen over Stokes werkkringen en verblijfplaatsen. In de oorkondenleer is namelijk een methode ontwikkeld om handen, die bekend zijn uit meer dan één stuk, te lokaliseren. Zoals hierboven al is gezegd, oorkonden zijn lang niet altijd geschreven door het personeel van de instantie die ze uitvaardigt, maar ze kunnen even goed zijn opgesteld, en ook gemundeerd, door personeel van de ontvangende partij. Volgens de regels van deze methode moet een scribent die twee of meer grafelijke oorkonden schrijft welke zijn bestemd voor verschillende ontvangers, werkzaam zijn geweest in de grafelijke kanselarij. Dat geldt ook voor de notarius die twee of meer stukken schrijft die bestemd zijn voor de graaf, maar uitgevaardigd door verschillende oorkonders ${ }^{98}$.

Een reconstructie van Stokes ambtelijke carrière volgens deze regels levert geen problemen op, althans voor wat betreft het tweede deel van zijn loopbaan, de periode 1300-1305. Zoals allang wordt aangenomen was hij toen inderdaad in dienst van de graven van Holland. Op 10 november 1299 stierf graaf Jan I, waarna zijn neef, graaf Jan van Henegouwen, zich opwierp als zijn opvolger in Holland. Om zijn aanspraken te versterken reisde deze Jan II in zijn nieuwe graafschap langs de belangrijkste steden, alwaar hij zich van de steun van de burgerij verzekerde. In iedere stad wisselden burgers en graaf oorkonden uit, waarin de eerstgenoemden verklaarden Jan als hun graaf te erkennen, terwijl deze op zijn beurt de oude stedelijke voorrechten bekrachtigde. Aan de hand van die reeks oorkonden is de inhuldigingstournee van Jan II precies te volgen. Eind november was hij in Middelburg, waama hij in december via Zierikzee, Geertruidenberg en Dordrecht noordwaarts trok, naar Delft, Leiden en Haarlem 99. Stoke nu sloot zich blijkbaar in Zierikzee aan bij het grafelijk gezelschap, want de oorkonden van en voor die stad zijn door hem geschreven, evenals alle volgende oorkonden op deze tocht.

Vanaf die tijd, tot aan zijn laatste gedocumenteerde werkzaamheden in 1305, bleef Stoke in grafelijke dienst. Hij fungeerde evenwel niet onafgebroken als scriptor van grafelijke stukken, want vrijwel alle oorkonden die hij schreef zijn uitgevaardigd in een vijftal korte perioden, die in lengte variëren van enkele weken tot een paar maanden. Ook binnen deze perioden van activiteit zijn de door hem gemundeerde oorkonden vaak geclusterd in groepjes van enkele kort na elkaar geschreven stukken. Misschien verrichtte Stoke alleen schrijfwerk wanneer er geen reguliere notarii aanwezig waren. In ieder geval verbleef hij niet constant in de omgeving van de graven, want hij vergezelde hen niet wanneer ze naar Henegouwen reisden: de door hem gemundeerde oorkonden zijn steeds in Hollandse of Zeeuwse steden uitgevaardigd. De drie laatste stukken van zijn hand, uit november 1305, zijn in Zierikzee geschreven. Dit laatste gegeven, in combinatie met het zojuist vermelde feit dat Stoke

98 Over deze methode zie Kruisheer, Oorkonden en kanselarij, I, 29-30, en uitvoeriger Kruisheer, 'Kanzleianfertigung', 256-300, i.h.b. 256-262; vgl. voorts noot 26.

99 Zie Gysseling, CMT, nos. 1815, 1826-1830, 1832, 1833, 1835-1837, en F. van Mieris, Groot charterboek der graaven van Holland, II, 3, 4. 
in diezelfde stad zich bij Jan II aansloot, lijkt een bevestiging van de onlangs door K. de Rijke geopperde Zierikzeese achtergrond van onze klerk ${ }^{100}$.

Voor de eerste periode van Stokes schrijfactiviteit, tussen juli 1296 en december 1299, ligt de zaak minder duidelijk. In die tijd schreef hij namelijk twee Dordtse schepenakten, bestemd voor verschillende ontvangers, alsmede een door Dordtse geestelijken uitgevaardigde oorkonde. Volgens de zojuist genoemde regels moet hij in die jaren dus werkzaam zijn geweest als een Dordtse stadsklerk. Hiermee in tegenspraak lijkt het feit dat hij in december 1298 en oktober 1299 twee oorkonden schreef ten behoeve van de Hollandse graaf ${ }^{101}$. Uit andere bronnen weten we echter dat Jan I juist in die maanden in Dordrecht verbleef ${ }^{102}$. Het heeft er dus alle schijn van dat de graaf toen gebruik heeft gemaakt van de diensten van een stadsklerk. Het is al met al het meest waarschijnlijk dat Stoke in de periode 1296-1299 in Dordrecht werkzaam was, en pas tijdens de eerder genoemde inhuldigingstocht van Jan II in grafelijke dienst is getreden.

$\mathrm{Nu}$ bekend is welke oorkonden door Melis Stoke zijn gemundeerd, kunnen we nog een stap verder gaan door ons te verdiepen in de tekst van die stukken. Met name is het van belang om vast te stellen of hierin sprake is van een aan Stoke eigen dictaat. Het dictaatonderzoek, eveneens ontwikkeld in de oorkondenleer, bestudeert de bewoording van steeds terugkerende zinswendingen in oorkonden. Oorkondeteksten bestaan namelijk voor een deel uit vaste formules, die worden gebruikt op bepaalde plaatsen binnen de oorkondetekst, met name in de aanhef ervan en aan het slot. Deze vaste formules kunnen zijn gesteld in een grote verscheidenheid van variante bewoordingen. Zo telde Kruisheer in de grafelijke oorkonden ruim 180 Latijnse en bijna 50 Nederlandse manieren om de formule 'Ik maak bekend dat' onder woorden te brengen. Wanneer nu in de door één hand gemundeerde oorkonden deze vaste formules'steeds of vaak op precies identieke wijze worden verwoord, dan is sprake van een eigen dictaat van die notarius. Daaruit kan weer worden geconcludeerd dat die betreffende scribent zelf zijn teksten redigeerde ${ }^{103}$.

Voor het onderzoek naar Stokes dictaat is uitsluitend naar zijn Nederlandse stukken gekeken: het geringe aantal Latijnse en Franse oorkonden laat ik hier buiten beschouwing. Inderdaad bleken in Stokes Nederlandse teksten precies identieke formuleringen dermate vaak aanwijsbaar dat we kunnen spreken van een eigen dictaat. Kenmerkend voor zijn dictaat is vooral de vaste combinatie van enkele steeds gebruikte formuleringen; afzonderlijk worden die ook wel bij andere scribenten aangetroffen, maar in dezelfde combinatie nooit. Dit eigen dictaat in de door Stoke gemundeerde oorkonden maakt in ieder geval duidelijk dat hij deze teksten zelf heeft opgesteld.

100 K. de Rijke, Melis Stoke, poorter van Zierikzee (Middelburg, 1989).

101 De grafelijke keur voor Beverwijk van november 1298 is door Kruisheer, Oorkonden en kanselarij, II, 409, no. 1001, ten onrechte aan kanselarijhand U toegeschreven; zie Burgers, 'Paleografie documentaire bronnen', kanselarijhanden $\mathrm{T}$ en $\mathrm{W}$.

102 Zie Kruisheer, Oorkonden en kanselarij, II, 409, no. 1002; 413, no. 1027.

103 Over het dictaatonderzoek zie Kruisheer, Oorkonden en kanselarij, I, 76-79, en II, 497-500. 
Als laatste stap in het dictaatonderzoek is onderzocht of we Stokes dictaat kunnen ontdekken in oorkonden die niet door hem zelf zijn gemundeerd, of in oorkonden waarvan we niet kunnen weten door wie ze zijn gemundeerd, omdat ze niet in origineel zijn overgeleverd, maar slechts in latere afschriften. Bij zo'n onderzoek moeten natuurlijk strenge maatstaven worden aangelegd; alleen de oorkonden die volledig Stokes dictaat vertonen zijn aan hem toegeschreven. Zo doende werden twaalf Nederlandstalige oorkonden gevonden met dat volledige dictaat, onder welke zich zoals gezegd ook het gesigneerde stuk uit 1304 bevindt. Wij mogen aannemen dat ook deze teksten door Stoke zijn opgesteld. Al deze twaalf stukken blijken slechts in afschrift te zijn overgeleverd; er is dus geen enkele oorkonde bekend met Stokes dictaatkenmerken, die is gemundeerd door een andere klerk. Hieruit volgt dat de kans groot is dat Stoke de betreffende stukken oorspronkelijk ook zelf heeft gemundeerd. De toeschrijving van deze oorkonden aan Stoke wordt bevestigd door het feit dat ze op twee na alle zijn uitgevaardigd binnen de eerdergenoemde korte perioden van zijn schrijfactiviteit. Ook voor de twee oorkonden die daarbuiten vallen is het aannemelijk dat ze door Stoke zijn vervaardigd: ze zijn namelijk bewaard gebleven als afschriften - of misschien kladontwerpen - in het oudste cartularium van de graven van Holland, en blijken daarin door Stoke eigenhandig te zijn ingeschreven ${ }^{104}$. Het dictaatonderzoek verschaft ten slotte nog een aanwijzing dat Stoke zijn carrière inderdaad begon als stadsklerk in Dordrecht: zijn dictaat vertoont duidelijk invloeden van de in de Dordtse oorkonden gebruikelijke formuleringen, en de door hem gemundeerde Nederlandstalige schepenakte uit 1296 is volledig in het Dordtse dictaat geredigeerd $^{105}$.

Samenvattend kunnen we stellen dat Melis Stoke van juli 1296 tot december 1299 te Dordrecht actief was als klerk. Begin december 1299 trad hij in dienst bij graaf Jan II, waarna hij tot november 1305 bij deze graaf en bij diens opvolger Willem III werkzaam was als kanselarijklerk. Hij mundeerde voor de grafelijkheid tientallen oorkonden, en de tekst van deze stukken werd door hem zelf opgesteld. Hij blijkt een ontwikkeld man te zijn geweest, want hij beheerste het Latijn en het Frans. De overgeleverde oorkonden van Stokes hand zijn bijna alle vervaardigd binnen een vijftal korte perioden, wat erop wijst dat hij naast zijn functie van oorkondenscriptor mogelijk ook andere taken vervulde in dienst van de graven.

De ontdekking van de door Stoke eigenhandig geschreven oorkonden, en de daaruit voortvloeiende nieuwe gegevens over zijn loopbaan als klerk, openen veelbelovende perspectieven voor verder onderzoek. Een paar van die onderzoeksmogelijkheden kunnen hier worden aangestipt; ze liggen zowel op het terrein van de medioneerlandistiek als dat van de geschiedschrijving. Zo is ooit door S. Hofker een dissertatie geschreven waarin zij, op basis van de tekst van de Rijmkroniek, Stokes taal analyseer$\mathrm{de}^{106}$. $\mathrm{Nu}$ is de kroniek alleen overgeleverd in latere kopieën, wat voor zulk een

104 Rijksarchief in Zuid-Holland, Graven van Holland, no. 2144, f. 35r.

105 Dijkhof, 'Oorkondenwezen kloosters en steden', hoofdstuk Dordrecht,

106 S. Hofker, De taal van Melis Stoke (Amsterdam, 1908). 
taalkundig onderzoek natuurlijk een ernstige handicap is. Het corpus van Stokes 34 Nederlandstalige autografe oorkondenteksten kan nu onze kennis van zijn taal belangrijk uitbreiden. Bovendien kan in die oorkonden worden onderzocht hoe Stoke in de praktijk te werk ging bij het opstellen van zijn teksten. Een aantal van zijn oorkonden bestaat namelijk uit series van kort na elkaar geschreven en vrijwel gelijkluidende stukken, en daarin blijken door hem voortdurend wijzigingen en verbeteringen te zijn aangebracht.

Verdere onderzoeksmogelijkheden worden geboden door de nieuwe gegevens over Stokes loopbaan te confronteren met de inhoud van de Rijmkroniek. Dit zou kunnen leiden tot een hernieuwde, nu mogelijk definitieve, poging tot beantwoording van de vraag of Stoke werkelijk de auteur is van de kroniek, of toch alleen maar de bewerker, zoals door H. C. Peeters is geponeerd ${ }^{107}$. Ook kan zo misschien meer worden gezegd over de positie van Stoke aan het grafelijk hof: was hij slechts een laaggeplaatste klerk die af en toe oorkonden schreef, of had hij een hogere rang, en was hij misschien zelfs lid van de grafelijke raad, zoals hij zelf in de Rijmkroniek lijkt te suggereren? Tenslotte hebben we zo meer mogelijkheden om de feitelijke betrouwbaarheid van de Rijmkroniek te toetsen, waarmee weer een bijdrage kan worden geleverd aan de actuele discussie over de waarde van deze en andere rijmkronieken als historische bron ${ }^{108}$.

Het is in ieder geval duidelijk dat we op al die manieren meer te weten zullen komen over de ingewikkelde ontstaansgeschiedenis van de Rijmkroniek, de receptie ervan, en de functie van het dichtwerk. Zo kan, met een paleografisch en diplomatisch onderzoek als uitgangspunt, onze kennis van deze belangrijke literaire en historische bron uiteindelijk aanzienlijk worden uitgebreid en verdiept.

107 H. C. Peeters, De rijmkroniek van Holland, haar auteur en Melis Stoke (Antwerpen, 1966).

108 Deze discussie is op gang gebracht door A. L. H. Hage, Sonder favele, sonder lieghen. Onderzoek naar vorm en functie van de Middelnederlandse rijmkroniek als historiografisch genre (Groningen, 1989). 


\section{Een harmonisch gezin en individuele ontplooiing. Enkele beschouwin- gen over veranderende opvattingen over de vrouw in Nederland sinds de jaren dertig*}

\section{J. C. H. BLOM}

'Wanneer de bruidegom zijn bruid de echtelijke woning binnenleidt, zingt het en jubelt het in zijn ziel. Het blozende bruidje weet en zwijgt. Beiden gaan zij het mysterie tegemoet'. Aan het woord is J. Waterink, hoogleraar in de pedagogiek aan de Vrije Universiteit. Het zijn de openingszinnen van zijn artikel 'Iets over ouders enkinderen' in het Nederlandsch Gezinsboek waarvan in 1936 de eerste druk verscheen. Dit boek was een produkt van samenwerking over de grenzen van de verzuiling heen. Het was bestemd om uit te reiken - al diende er wel voor betaald te worden — aan hen die huwelijksaangifte deden. Een flink aantal gemeenten gaf daaraan medewerking. De uitgave was dan ook een succes. In 1939 bleek de eerste druk van 30.000 exemplaren uitverkocht. Een nieuwe herziene en uitgebreide druk werd uitgebracht in een oranje band met gekroonde blauwe Nederlandse leeuw 1.

Anders dan het openingscitaat doet vermoeden gaat het om een overwegend praktisch georiënteerd boek, dat op allerlei terreinen, maar met een nadruk op gezondheid en opvoeding, voorlichting gaf. Als zodanig paste het in de brede stroom voorlichtingsen opvoedingsactiviteiten die de Nederlandse geschiedenis al sinds jaar en dag rijk was. De auteurs en leden van het bestuur, onder auspiciën waarvan de uitgave tot stand kwam, waren afkomstig uit diverse kringen. Zo werkte naast Waterink het bekende vrijzinnig-democratische kamerlid mevrouw B. Bakker-Nort mee. In haar bijdrage over het huwelijksrecht stak zij niet onder stoelen of banken dat zij voorzitster was van het Comité vooreen gemeenschappelijke actie tot hervorming onzer huwelijkswetgeving $^{2}$. Dit Comité wilde het beginsel van de maritale macht vervangen door het principe van gelijkwaardigheid en gelijkgerechtigdheid der echtgenoten. Ook bijdragen over 'Geneeskundig onderzoek voor het huwelijk' en 'Erfelijkheid en Eugenetica' wijzen niet op eenzijdig confessionele achtergrond. Eerder het tegendeel. Medische deskundigheid overheerste. Vandaar wellicht wel aandacht voor zwangerschap, kraambed en de verzorging van de zuigeling, maar zwijgzaamheid over wat daaraan

* Grote dank komt toe aan G. Alberts, O. P. Blom, J. Kennedy, M. Schwegman, G. van Vegchel, H. Vossen en J. Withuis voor stimulerend commentaar op een eerdere versie van deze tekst, die in feite werd afgesloten begin 1992. Sindsdien zijn nog slechts marginale veranderingen aangebracht en enkele literatuurverwijzingen toegevoegd.

1 Nederlandsch Gezinsboek (2e herziene druk, Amsterdam, [1939]). Citaat blz. 1. Het door mij geraadpleegde exemplaar werd, in de oranje uitvoering met gekroonde leeuw, op 12 februari 1942 uitgereikt aan mijn ouders (kosten f1,50). Over Waterink zie E. Mulder, Beginsel en beroep. Pedagogiek aan de Universiteit in Nederland 1900-1940 (Diss. UvA, 1989) 191-227, en J. C. Sturm, Een goede gereformeerde opvoeding. Over neo-calvinistische moraalpedagogiek (1880-1950) met speciale aandacht voor de nieuw-gereformeerde jeugdorganisaties (Kampen, 1988).

2 Nederlandsch Gezinsboek, 135-143. 